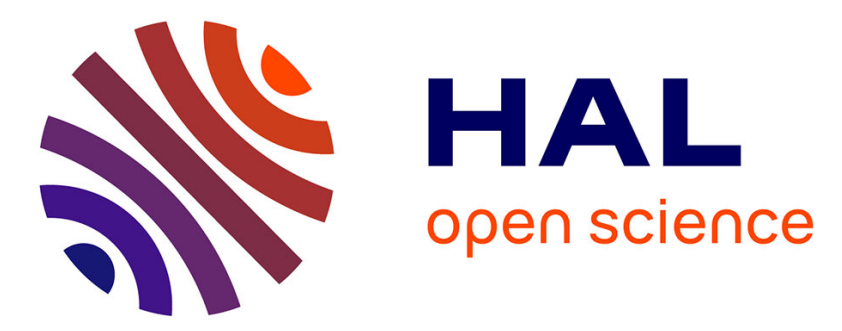

\title{
Sub-National Allocation of COVID-19 Tests: An Efficiency Criterion with an Application to Italian Regions
}

C. Baunez, Mickael Degoulet, Stéphane Luchini, Patrick Pintus, Miriam Teschl

\section{To cite this version:}

C. Baunez, Mickael Degoulet, Stéphane Luchini, Patrick Pintus, Miriam Teschl. Sub-National Allocation of COVID-19 Tests: An Efficiency Criterion with an Application to Italian Regions. 2020. hal-02544388

\section{HAL Id: hal-02544388 \\ https://hal-amu.archives-ouvertes.fr/hal-02544388}

Preprint submitted on 17 Apr 2020

HAL is a multi-disciplinary open access archive for the deposit and dissemination of scientific research documents, whether they are published or not. The documents may come from teaching and research institutions in France or abroad, or from public or private research centers.
L'archive ouverte pluridisciplinaire HAL, est destinée au dépôt et à la diffusion de documents scientifiques de niveau recherche, publiés ou non, émanant des établissements d'enseignement et de recherche français ou étrangers, des laboratoires publics ou privés. 


\section{amse}

école d'économie d'aix-marseille

aix-marseille school of economics

\section{Working Papers / Documents de travail}

Christelle Baunez Mickael Degoulet Stéphane Luchini

Patrick A. Pintus Miriam Teschl 


\title{
Sub-National Allocation of COVID-19 Tests: An Efficiency Criterion with an Application to Italian Regions *
}

\author{
Christelle Baunez \& Mickael Degoulet ${ }^{\dagger}$ \\ Stéphane Luchini, Patrick A. Pintus \& Miriam Teschl ${ }^{\ddagger}$
}

April 16, 2020

\begin{abstract}
Tests are crucial to know about the number of people who have fallen ill with COVID19 and to understand in real-time whether the dynamics of the pandemic is accelerating or decelerating. But tests are a scarce resource in many countries. The key but still open question is thus how to allocate tests across sub-national levels. We provide a data-driven and operational criterion to allocate tests efficiently across regions or provinces, with the view to maximize detection of people who have been infected. We apply our criterion to Italian regions and compute the shares of tests that should go to each region, which are shown to differ significantly from the actual distribution.
\end{abstract}

JEL Classification Numbers: I18; H12

Keywords: COVID-19; Epidemic Dynamics; Acceleration of Harm; Deceleration of Harm; Real-time Analysis; Sub-National Allocation of Tests; Efficiency Criterion; Italy

\footnotetext{
*This work was supported by French National Research Agency Grants ANR-17-EURE-0020.

${ }^{\dagger}$ Aix-Marseille University, CNRS, Institut Neuroscience Timone. Email addresses: mickael.degoulet@univamu.fr, christelle.baunez@univ-amu.fr

${ }^{\ddagger}$ Aix-Marseille University, CNRS, EHESS, Centrale Marseille, Aix-Marseille School of Economics. Email addresses: stephane.luchini@univ-amu.fr, patrick.pintus@univ-amu.fr, miriam.teschl@ehess.fr
} 


\section{Introduction}

Testing is crucial to detect people with SARS-CoV-2, the virus responsible for the COVID 19 pandemic (see e.g. [1], [2], [6], 3], [15]). In this vein, on March 16 th 2020, the Director-General of the WHO strongly advised countries to "test, test, test" because "a fire cannot be fought blindfolded" 1 But in many countries, tests are too scarce a resource to guarantee widespread and comprehensive testing (see e.g. [14]). Countries have set up guidelines spelling out the priority of who should get tested given that not all people can be tested. But this is only one side of the story and does not address the question of how to allocate a limited amount of tests across sub-national levels. We provide in this paper a data-driven and operational criterion that distributes tests according to how the virus spreads during the pandemic in different geographical units that either accelerate or decelerate.

The idea of the criterion is to base the allocation decision of a limited number of tests on data about the marginal benefit of an additional test. Such marginal benefit can be measured directly on the basis of a function representing the dynamics of the pandemic. Such a function is estimated using data on the numbers of both COVID-19 confirmed cases and total tests. Section 2 explains what information is necessary to calculate this function in real-time and how to derive the weights for the distribution of tests on a sub-national level. In Section 3 we apply this criterion to Italian regions, where certain regions struggle more than others with the pandemic. We compute the optimal shares of tests for each region and compare it with the actual distribution. Our main conclusion is that there is room for significant improvement in the geographical allocation of COVID-19 tests across Italian regions.

An important point of our approach is that it does not provide predictive model but rather relates to now-casting analysis. Forecasting models typically have many parameters, are highly uncertain at times of unknown and new events and can fall prey to estimation errors. Our datadriven criterion builds upon non-parametric estimation and as such constitutes an important realtime source of information for decision-makers, complements traditional epidemiological models and is amenable to public health analysis.

\section{Characterization of the Testing Allocation Criterion}

Our criterion builds upon a new approach that is designed to monitor and respond to a pandemic like COVID-19 (see [13]). The approach organises the data in real time in order to detect whether an ongoing pandemic is accelerating or decelerating. It is based on the idea that in times of uncertainty, when it is difficult to have good knowledge on probabilities and thus difficult to make reliable forecasting models, decisions have to be based on the information available more than anything else. Following [17] and [13], the question is how we can use available information to

\footnotetext{
${ }^{1}$ https://www.who.int/dg/speeches/detail/who-director-general-s-opening-remarks-at-the-media-briefing-oncovid-19-16-march-2020-last access April 14 ${ }^{\text {th }} 2020$
} 
Figure 1: Epidemic Dynamics in Two Hypothetical Regions with Different Dynamics

(a) Region Q

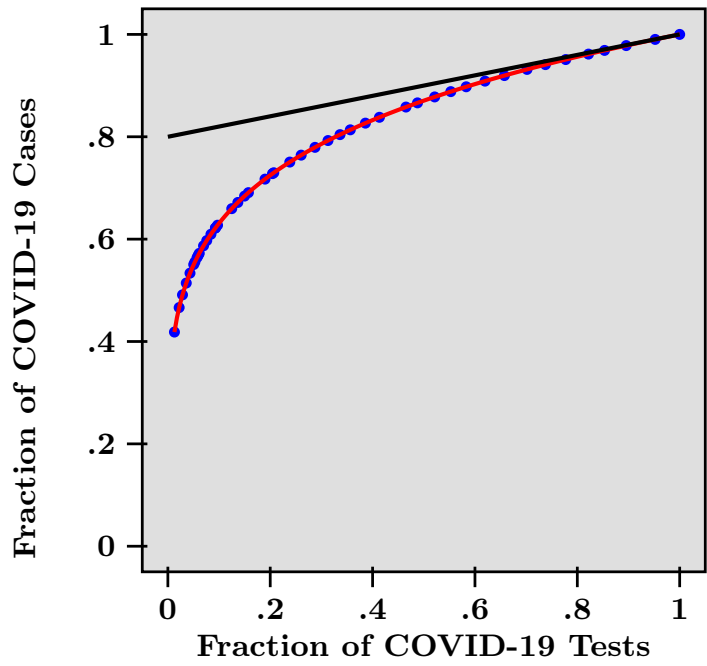

(b) Region S

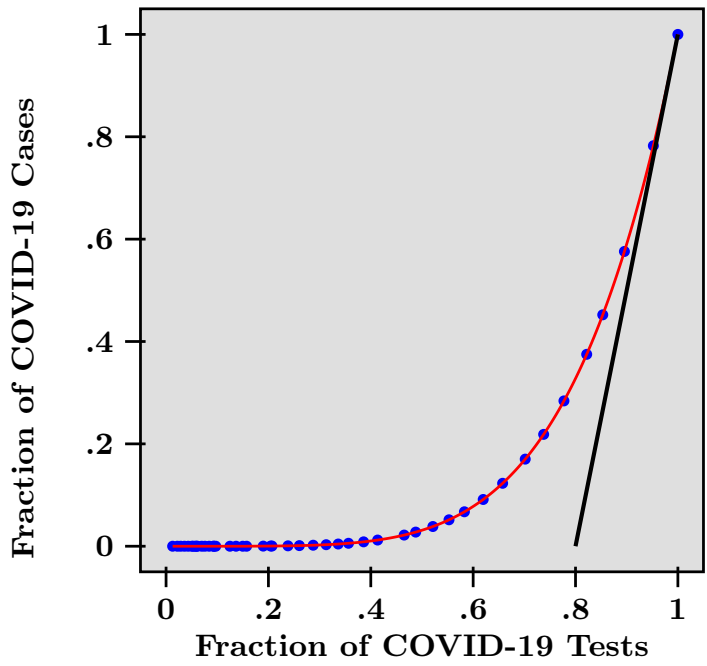

Note: Blue dots represent the Fraction of Total COVID-19 Cases ( $y$-axis) against Fraction of COVID-19 Tests ( $x$-axis) across Time, for Region $Q$ in panel (a) and Region $S$ in panel (b). Fraction of realised tests (resp. of cases) equals the cumulative number of tests realised (resp. cases) on day $t$ divided by the cumulative number of tests (resp. cases) realised at the end date $T$ - Red lines are the functional relationship between positive cases and total tests and depict the dynamic of the pandemic - Black Lines are the tangent lines od the functions in red at end point, the slopes of which measure the marginal benefits of testing at end point.

detect acceleration or deceleration of harm in the current case of the pandemic. To answer this question the number of tests is crucial. Tests allow visualising the spread of the pandemic and are therefore a precondition for a reliable real-time analysis. If ever more cases of infected people are detected with an increasing number of total tests, the pandemic is accelerating. If, on the contrary, ever fewer infected people are detected with an increasing number of test, the pandemic is decelerating. This insight can be visualised by plotting the cumulated number of cases that have been tested positively against the cumulated number of total tests. The convexity of such functional relationship indicates acceleration, concavity deceleration. This is an important realtime guide for health policy decisions that aim to curb the pandemic: what health policy decision want to achieve and to keep is a concave functional relationship of positively tested subjects to total tests and eventually a flat relationship that indicates the end of the pandemic $2^{2}$

We illustrate our approach by considering the following hypothetical example. A country has been subject to an epidemic like COVID-19 for several weeks. This country is composed of two regions labeled, say, Q and $\mathrm{S}$. While in region $\mathrm{Q}$, the virus spread rapidly from very early on, region $\mathrm{S}$ only saw a few cases at the beginning but experienced subsequently a rapid increase of infected people.

${ }^{2}$ Tests may also be an important health policy response to contain the pandemic, but this is not what we are discussing here. In this paper, testing allows to know about the pandemic spread whatever the health policy response put in place. 
The pandemic has followed different dynamics across the two regions and the resulting heterogeneity is best visualized in Figure 1. Figure 1 depicts a scatter-plot of the number of COVID-19 tests against the number of COVID-19 cases, using daily data from two hypothetical regions $\mathrm{Q}$ and $\mathrm{S}$, at a given date that we think of as today (the blue dots). Both the number of cases and the number of tests are normalized by dividing raw data over the last data point available today. The red lines in Figure 1 are the functional relationship between positive cases and total tests and thus represent the dynamics of the pandemic in each region. While in Figure 1 panel (a) this line is concave and indicates that tests find ever fewer infected people, in Figure 1 panel (b), the line is convex and points to the fact that tests find ever more cases of infected people. Said differently, what testing tells us is that while in region $\mathrm{Q}$ the pandemic is decelerating, in region $\mathrm{S}$ it is accelerating.

With that interpretation in mind, deriving a criterion for allocating a given number of tests across the two regions is straightforward. The most important information is the marginal benefit of an additional test in each region. Knowing this, it is possible to compute the proportion of total available tests at the national level that each region should get. It should be obvious that a larger fraction of tests should go to the region where the marginal test is higher.

In Figure 1, the marginal benefit of a test is measured by the slope of the tangent of each curve at $x=1$, which is the end point of each graph $3^{3}$ Marginal benefits are depicted as the black lines, tangent to the red curve in Figure 1 panels (a) and (b). Given the steepness of the tangent in Figure 1 panel (b) due to the acceleration of the pandemic, it is obvious that more tests should be done in region $\mathrm{S}$ than in region $\mathrm{Q}$. Both curves in Figure 1 are the graphs of power function, so that in this example the slope at $x=1$ is directly given by the exponent, which equals 0.2 for region $\mathrm{Q}$ and 5 for region $\mathrm{S}$. These numbers are interpreted as follows. In region $\mathrm{Q}$, the most recent $10 \%$ of the total number of test have helped uncover $2 \%$ (that is, $0.2 \times 10$ ) of total confirmed infections. This is much less than in region $\mathrm{S}$, where the most recent $10 \%$ are associated with the detection of $50 \%$ (that is, $5 \times 10$ ) of the total number of COVID-19 cases. In that sense, more testing is needed in region $\mathrm{S}$ than in region $\mathrm{Q}$. Therefore, given that the marginal benefit of an additional test in region $\mathrm{S}$ is 25 (that is, 5/0.2) times higher than in region Q, the number of total tests available today should be divided as follows. Region $\mathrm{S}$ would get about $96 \%$ (that is, $5 / 5.2$ ) while region $\mathrm{Q}$ would get the remainder $4 \%$ (that is, $0.2 / 5.2$ ).

It goes without saying that shares should be updated regularly, following changes in the marginal benefits/slopes of some regions relative to others. Although the above weights do not take into account population in each region, it is straightforward to combine them with population weights, as we now show. We summarize below, for convenience, the steps to compute such weights and the corresponding share for each sub-national level, $i=1, \ldots, n$ :

\footnotetext{
${ }^{3}$ The marginal benefit of testing as defined here is reminiscent of distributional weights used in public policy analysis-see [7] for a discussion on distributional weights for health policies.
} 


\section{Criterion to allocate COVID-19 tests across sub-national levels}

$i=1, \ldots, N$, with population $n_{i}$ :

- for each sub-national level $i$, estimate a smooth curve from the scatterplot of the number of confirmed COVID-19 cases against the number of COVID-19 tests across time. Estimate next at end point, that is, at the latest date for which data is available, the slope of such a curve for each $i$, which delivers a weight $w_{i}$

- each sub-national level $i$ should receive a share of the total number of tests available at the national level that is defined by $A_{i}=\frac{w_{i} n_{i}}{\sum_{i}^{n} w_{i} n_{i}}$, taking into account population. Alternatively, such a share is defined as $a_{i}=\frac{w_{i}}{\sum_{i}^{n} w_{i}}$ if population is not accounted for.

\section{An Application to Italian Regions}

Italy is in a national lock-down period since March $9^{\text {th }}$ 2020. About a month later, the number of newly detected cases are decreasing every day on a national level. However, across regions, the pandemic spread was and still is not uniform. As it is commonly known, regions such as Lombardia and Veneto have seen very high numbers of infected people as well as deaths, whereas more southern regions have had much fewer cases. Although testing has been deficient at the early stage of the pandemic (see [14]), Italy has successively implemented an aggressive testing strategy reaching a total of over a million tests by mid-April. These are many tests but still a low number for a population of about 60 million inhabitants. Given this limited number of possible tests for a large population, the crucial but still open question is how to distribute tests efficiently, in particular in view of the differences in pandemic dynamics across regions.

The data we use is made publicly available by the Italian Department of Civil Protection 4 from which can be accessed the official dashboard that monitors the situation of the COVID-19 pandemic in Italy ("Mappa della situazione"). This map provides the link to data that contains information on all Italian regions 5 There are 20 regions, but the data has 21 entries because the region of Trentino-Alto Adige counts for two to take account of the two autonomous provinces (P.A.) that form that region, named P.A. Bolzano and P.A. Trento in the data set. From this dataset, we use the information on the total number of tests performed ("tamponi") and the total number of positive cases ("totale casi") for each region, which is updated on a daily basis.

\footnotetext{
${ }^{4}$ http://www.protezionecivile.gov.it/home last access April $14^{\text {th }} 2020$

5 https://github.com/pcm-dpc/COVID-19/tree/master/dati-regioni last access April $14^{\text {th }} 2020$
} 
Figure 2: Optimal Allocations of tests in Italian regions as compared to actual allocation

\begin{tabular}{|c|c|c|}
\hline$\left(n_{1}=\begin{array}{r}\text { Abruzzo } \\
1311580)\end{array}\right.$ & $\begin{array}{l}a_{1}=8.85 \\
A_{1}=3.99 \\
x_{1}=1.97\end{array}$ & 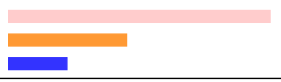 \\
\hline $\begin{array}{r}\text { Basilicata } \\
\left(n_{2}=562869\right)\end{array}$ & $\begin{array}{l}a_{2}=7.59 \\
A_{2}=1.47 \\
x_{2}=0.41\end{array}$ & 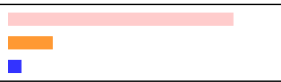 \\
\hline$\left(n_{3}=\begin{array}{r}\text { Calabria } \\
1947131)\end{array}\right.$ & $\begin{array}{l}a_{3}=3.36 \\
A_{3}=2.25 \\
x_{3}=1.85\end{array}$ & + \\
\hline $\begin{array}{r}\text { Campania } \\
\left(n_{4}=5801692\right)\end{array}$ & $\begin{array}{l}a_{4}=1.89 \\
A_{4}=3.78 \\
x_{4}=3.44\end{array}$ & +2 \\
\hline $\begin{array}{l}\text { Emilia-Romagna } \\
\quad\left(n_{5}=4459477\right)\end{array}$ & $\begin{array}{l}a_{5}=3.76 \\
A_{5}=5.76 \\
x_{5}=3.86\end{array}$ & + \\
\hline $\begin{array}{l}\text { Friuli-Venezia Giulia } \\
\qquad\left(n_{k}=1215220\right)\end{array}$ & $\begin{array}{l}a_{6}=7.22 \\
A_{6}=3.02 \\
x_{6}=3.86\end{array}$ & + \\
\hline $\begin{array}{r}\text { Lazio } \\
\left(n_{7}=5879082\right)\end{array}$ & $\begin{array}{l}a_{7}=6.36 \\
A_{7}=12.86 \\
x_{7}=6.70\end{array}$ & +2 \\
\hline $\begin{array}{r}\text { Liguria } \\
\left(n_{8}=1550640\right)\end{array}$ & $\begin{array}{l}a_{8}=6.31 \\
A_{8}=3.36 \\
x_{8}=2.18\end{array}$ & +2 \\
\hline $\begin{array}{r}\text { Lombardia } \\
\left(n_{9}=10060574\right)\end{array}$ & $\begin{array}{l}a_{9}=4.93 \\
A_{9}=17.06 \\
x_{9}=20.85\end{array}$ & 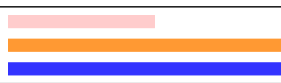 \\
\hline $\begin{array}{r}\text { Marche } \\
\left(n_{10}=1525271\right)\end{array}$ & $\begin{array}{l}a_{10}=5.89 \\
A_{10}=3.09 \\
x_{10}=2.17\end{array}$ & + \\
\hline$\left(n_{11}=305617\right)$ & $\begin{array}{l}a_{11}=0.15 \\
A_{11}=0.02 \\
x_{11}=0.233\end{array}$ & 1 \\
\hline $\begin{array}{l}\text { P.A. Bolzano } \\
\left(n_{12}=520891\right)\end{array}$ & $\begin{array}{l}a_{12}=2.96 \\
A_{12}=0.52 \\
x_{12}=2.34\end{array}$ & $\square$ \\
\hline $\begin{array}{r}\text { P.A. Trento } \\
\left(n_{13}=538223\right)\end{array}$ & $\begin{array}{l}a_{13}=6.11 \\
A_{13}=1.13 \\
x_{13}=1.64\end{array}$ & + \\
\hline$\left(n_{14} \begin{array}{r}\text { Piedmont } \\
=\end{array} 4356406\right)$ & $\begin{array}{l}a_{14}=4.50 \\
A_{14}=6.73 \\
x_{14}=6.02\end{array}$ & +2 \\
\hline $\begin{array}{r}\text { Apulia } \\
\left(n_{15}=4029053\right)\end{array}$ & $\begin{array}{l}a_{15}=4.70 \\
A_{15}=6.51 \\
x_{15}=3.05\end{array}$ & +2 \\
\hline$\left(n_{16}=\begin{array}{r}\text { Sardinia } \\
1639591)\end{array}\right.$ & $\begin{array}{l}a_{16}=4.55 \\
A_{16}=2.56 \\
x_{16}=1.04\end{array}$ & + \\
\hline $\begin{array}{r}\text { Sicila } \\
\left(n_{17}=4999891\right)\end{array}$ & $\begin{array}{l}a_{17}=4.83 \\
A_{17}=8.30 \\
x_{17}=3.35\end{array}$ & + \\
\hline$\left(n_{18}=\begin{array}{l}\text { Toscana } \\
3729641)\end{array}\right.$ & $\begin{array}{l}a_{18}=3.79 \\
A_{18}=4.85 \\
x_{18}=7.58\end{array}$ & + \\
\hline$\left(n_{19}=\begin{array}{r}\text { Umbria } \\
882015)\end{array}\right.$ & $\begin{array}{l}a_{19}=2.80 \\
A_{19}=0.85 \\
x_{19}=1.76\end{array}$ & 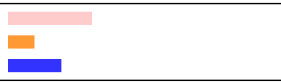 \\
\hline $\begin{array}{l}\text { Valle d'Aosta } \\
\left(n_{20}=125666\right)\end{array}$ & $\begin{array}{l}a_{20}=2.46 \\
A_{20}=0.11 \\
x_{20}=0.36\end{array}$ & 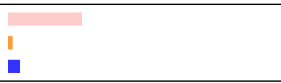 \\
\hline$\left(n_{21}=4905854\right)$ & $\begin{array}{l}a_{21}=6.99 \\
A_{21}=11.78 \\
x_{21}=20.21\end{array}$ & 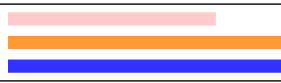 \\
\hline
\end{tabular}

Note: The figure presents the optimal allocations for each region as well as the mean actual allocation of tests in the last three days in the region $\left(x_{i}, i \in 1 \ldots 21\right), n_{i}, k \in 1 \ldots 21$, is the number of inhabitants in the region. $a_{i}, i \in 1 \ldots 21$, is the optimal allocation that does not account for population size whereas $A_{i}, i \in 1 \ldots 21$, is the optimal allocation that ponderates by population size $n_{i}$. Pink (resp. orange and blue) bar represents the optimal allocation (resp. the optimal allocation weighted by population size and the mean actual allocation).

We estimate both the functional relationship between the total number of tests and the total number of positive case for each region and its first derivative non-parametrically by local polynomial regression fitting with Epanechnikov weights [16]. The method allows to fit a smooth curve 
relating tests and cases without imposing restrictive parametric restrictions on the functional form [10]. We report in Figure 2 the estimated (population-unweighted) optimal shares $a_{i}, i=1 \ldots 21$, and the (population-weighted) optimal shares $A_{i}, i=1 \ldots 21$, using the mean estimate of the first derivative on the last 2.5\% of output design points (see Appendix A and B for the detailed results). We also report as a benchmark the mean actual allocation of tests in the last three days of the observed sample, for comparison purpose.

In Figure 2, each line represents an Italian region, whose population $n_{i}$ appears in parentheses under the name of the region in the first column. In the second column we report the populationweighted and population-unweighted shares, respectively, $A_{i}$ and $a_{i}$, as well as the actual share denoted $x_{i}$. The third column helps visualising those shares. As can be seen in Figure2, differences between the optimal shares as computed by using our (population-weighted and unweighted) criterion and actual shares of tests in all regions are significant. A striking conclusion is that certain regions currently receive too many tests, compared to others who have received too little. In particular, a substantial share of tests conducted in regions such as Lombardia, Veneto and Emilia-Romagna, where the pandemic spread more rapidely at the beginning, should be allocated to other regions. This is particularly true if we consider the population-unweighted share $a_{i}$ of tests but also if we take the population-weighted share $A_{i}$ into account. However, what also becomes apparent is that Lombardia and Veneto have currently about the same share of total tests allocated (about 20\% each) despite the fact that Veneto has only about half of the population of Lombardia. Our population-weighted criterion $A_{i}$ takes this into account and allocates more tests to Lombardia than to Veneto given its population size. If we continue to focus on the populationweighted share $A_{i}$, another striking example are the regions of Lazio, but also Sicily, which should receive a much larger share of tests, given the number of inhabitants in those regions, than they currently do. Indeed, Lazio, the second most populated region, should receive twice as many tests as it currently does, that is about $13 \%$ of the total number of Italian tests. This is because both its marginal benefit of testing and its regional population are among the largest across Italy. Sicily is in a similar situation and should also get twice as many tests. Generally, in view of Figure

2, it is hard to conclude that tests have been allocated across Italian regions where they are the most efficient and mostly needed. Obviously, to achieve the goal of efficient distribution of tests, it is important that regional governments and administrations are team-players and a nation-wide coordination is possible.

\section{Conclusion}

In this paper, we provide a data-driven and operational criterion that allows to distribute efficiently a limited amount of tests across sub-national units, depending on the dynamic of the pandemic. This allocation enhances the likelihood of detecting the largest possible number of infected persons. Knowing about the number of infected people is crucial to understand in real-time whether the 
dynamics of pandemic is accelerating or decelerating. If with an increasing number of tests ever more positive cases are found, the harm of the pandemic is accelerating. If with an increasing number of tests the number of detected positive cases declines on a daily basis, the pandemic starts to be contained and harm decelerates. We represented this in terms of a scatter-plot of total number of positive cases over total number of tests and pointed to the curvature of the underlying functional relationship. The pandemic ends when further tests do not find any new positive cases and the functional relationship becomes a flat line. The test-distribution criterion uses the information of the tangent to this functional form at endpoint, which we claim is a useful measure of the marginal benefit of testing. The policy implication of our criterion is that more tests will be needed in regions where the tangent is steeper and indicates an acceleration of the pandemic in comparison to regions where the tangent is flatter and thus means that the pandemic is spreading less quickly. Our criterion could be combined with group or pool testing (see [11] and [9]) and drive-in testing ([12] and [19]) so as to use the limited amount of test capacity in a best way in each region or province. Pool testing is currently developed and implemented in Germany ([8]) and Israe $]^{6}$ We show how the criterion can be applied to Italy and its regions where the pandemic had a very different dynamic. We find that the current actual allocation of tests across regions is not efficient with respect to the criterion we provide in this paper. In particular, there should be a shift in testing from certain regions where the pandemic at first spread very quickly but has subsequently been more and more controlled, to some of those regions where the pandemic started out slower, but seems to speed up more recently.

Although our application makes use of Italian data, a similar exercise could obviously be done for other countries where more fine-tuned regional data is available. Using such a criterion will be particularly important at a moment where certain countries start considering to remove at least some aspects of the lock-down. Removing the lock-down will certainly trigger a change in the dynamic of the pandemic and it is crucial to have real-time evaluations of the re-opening of the social and economic life as well as a tool to allocate tests efficiently within the country. It goes without saying that this criterion could also be used across nations and in particular for political unions such as the European Union to efficiently allocate tests across member countries. It has become clear quite soon that certain countries were better prepared for testing from very early on than others. In this context, it turns out that the often cited aspect of "European solidarity" may have most usefully been an economic principle of efficient testing.

https://www.timesofisrael.com/to-ease-global-virus-test-bottleneck-israeli-scientists-suggest-pooling-samples/ 


\section{References}

[1] Bedford J., Enria D., Giesecke J., et al. COVID-19 (2020): Towards Controlling of a Pandemic. The Lancet S0140-6736(20)30673-5. Available at https://doi.org/10.1016/ S0140-6736(20)30673-5

[2] Binnicker, M.J. (2020): Emergence of a Novel Coronavirus Disease (COVID-19) and the Importance of Diagnostic Testing: Why Partnership between Clinical Laboratories, Public Health Agencies, and Industry Is Essential to Control the Outbreak. Clinical Chemistry hvaa071 Available at https://doi.org/10.1093/clinchem/hvaa071

[3] COVID-19 National Emergency Response Center, Epidemiology and Case Management Team, Korea Centers for Disease Control and Prevention (2020): Contact Transmission of COVID-19 in South Korea: Novel Investigation Techniques for Tracing Contacts. Osong Public Health Res Perspect 2020, 11:60-63. Available at https://doi.org/10.24171/j.phrp. 2020.11.1.09

[4] De Brabanter, K., and Liu, Y. (2015): Smoothed Nonparametric Derivative Estimation Based on Weighted Difference Sequences, In Stochastic Models, Statistics and Their Applications, A. Steland, E. Rafajlowicz, K. Szajowski (Eds.), Chapter 4 (pp. 31-38), Springer.

[5] ECDC technical report (2020): Guidelines for the use of non-pharmaceutical measures to delay and mitigate the impact of 2019-nCoV. European Center for Disease Countrol. https://www.ecdc.europa.eu/sites/default/files/documents/ novel-coronavirus-guidelines-non-pharmaceutical-measures_0.pdf

[6] Fineberg, H.V. (2020): Ten Weeks to Crush the Curve. New England Journal of Medicine 10.1056/NEJMe2007263. Available at https://www.nejm.org/doi/full/10.1056/ NEJMe2007263

[7] Fleurbaey, M, Luchini, S., Muller, C. and E. Schokkaert (2013): Equivalent Income and fair evaluation of health care. Health economics, 22(6) 711-729. Available at https:// onlinelibrary.wiley.com/doi/abs/10.1002/hec.2859

[8] Seifried, E., Ciesek, S., et al. (2020): Pool testing of SARSCoV-02 samples increases worldwide test capacities many times

over. Available at https://aktuelles.uni-frankfurt.de/englisch/
pool-testing-of-sars-cov-02-samples-increases-worldwide-test-capacities-many-times-over/

[9] Gollier, C., and Gossner, O. (2020): Group Testing against Covid-19. CREST working paper 2020-04. Available at http://crest.science/RePEc/wpstorage/2020-04.pdf

[10] Harrel, F.Z. Jr (2015). Regression Modeling Strategies: With Applications to Linear Models, Logistic and Ordinal Regression, and Survival Analysis. Springer. 
[11] Jain, B.N., and Jain, T. (2020). Accelerated Infection Testing at Scale: a Proposal for Inference with Single Test on Multiple Patients. Available at https://arxiv.org/ftp/arxiv/ papers/2003/2003.13282.pdf

[12] Kwon, K.T., Ko J.H., Shin H., Sung M., Kim J.Y. (2020): Drive-Through Screening Center for COVID-19: a Safe and Efficient Screening System against Massive Community Outbreak. Journal of Korean Medical Science 35:e123. Available at https://doi.org/10.3346/jkms. $2020.35 . e 123$

[13] Luchini, S., Teschl, M., Pintus, P.A., Baunez, C., Degoulet, M., and Moatti, J.P. (2020): Urgently Needed for Policy Guidance: An Operational Tool for Monitoring the COVID-19 Pandemic. AMSE working paper 2020-09, available at https://ssrn. com/abstract=3563688 and https://www .amse-aixmarseille.fr/en/research/working-papers

[14] Rosenbaum, L. (2020): Facing Covid-19 in Italy - Ethics, Logistics, and Therapeutics on the Epidemic's Front Line. New England Journal of Medicine 10.1056/NEJMp2005492. Available at https://doi .org/10.1056/NEJMp2005492

[15] Salathé M., Christian A., Richard N., et al. COVID-19 (2020): Epidemic in Switzerland: on the Importance of Testing, Contact Tracing and Isolation. Available at https://doi.org/ $10.4414 / \mathrm{smw} .2020 .20225$

[16] Seifert, B., Brockmann, M., Engel, J. and T. Gasser (1994) Fast algorithms for nonparametric curve estimation. J. Computational and Graphical Statistics 3, 192-213. Available at https: //www.tandfonline.com/doi/abs/10.1080/10618600.1994.10474638

[17] Taleb, N. (2012). Antifragile, things that gain from disorder. Random House.

[18] Watkins, J. (2020): Preventing a covid-19 pandemic. BMJ 368:m810. Available at https: //doi.org/10.1136/bmj.m810

[19] Won, J., Lee S., Park M., et al. (2020): Development of a Laboratory-safe and Low-cost Detection Protocol for SARS-CoV-2 of the Coronavirus Disease 2019 (COVID-19). Experimental Neurobiology 10.5607/en20009. Available at https://doi.org/10.5607/en20009 


\section{A Epidemic Dynamics in Italian Regions}

In the following figures, we present for each region a scatter-plot of the raw data as well as of the non parametric estimation of the functional relationship between the fraction of COVID-19 tests tests and the fraction of COVID-19 cases. The fraction of COVID-19 tests is the daily obervation of the cumulative sum of tests divided by the total number of tests observed at the end date. The fraction of COVID-19 cases is the daily observation of the cumulative sum of positive cases divided by the total number of cases observed at the end date. Blue dots correspond to raw data. Each blue dot corresponds to a daily observation. The lowest dot (down, left) on on each Figure is the first date and the highest (up, right) dot corresponds to the end date. The red line is the non parametric estimation of the functional relationship between tests and cases using local polynomial regression fitting with Epanechnikov weights. The plain line in black is the tangent line derived from the end point from a non-parametric estimate of the first derivative of the functional relationship. The dashed line is the tangent line obtained from the mean first derivative estimate of the last $2.5 \%$ output design points and the dotted line is the tangent line derived from the mean first derivative estimate of the $10 \%$ output design points - see Appendix B for numerical results. 
(1) Abruzzo

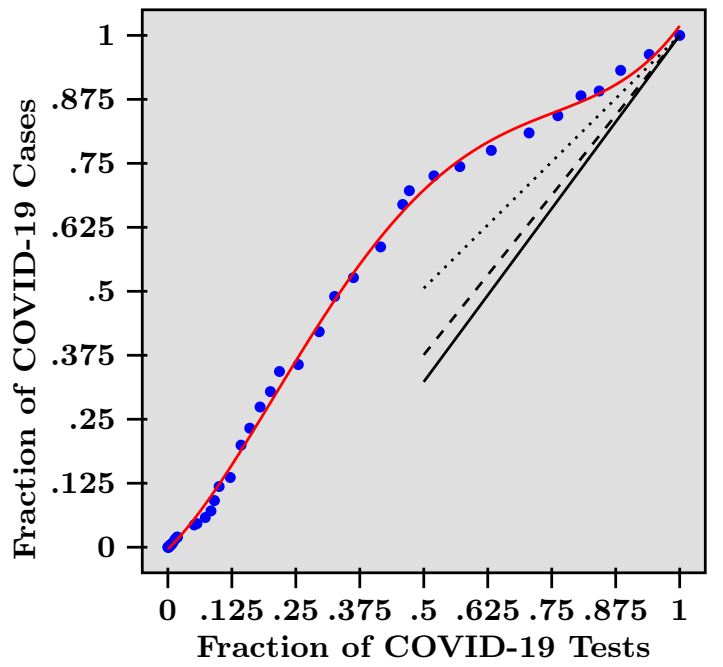

(3) Calabria

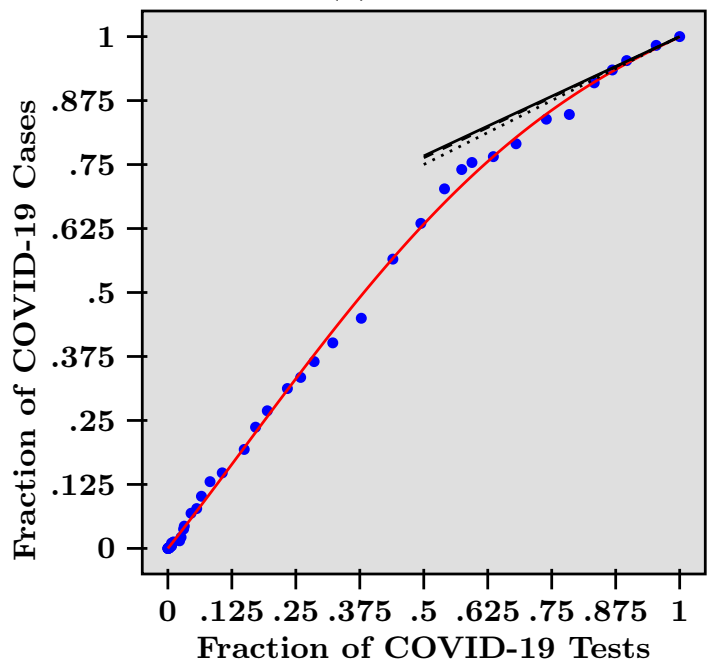

(5) Emilia-Romagna

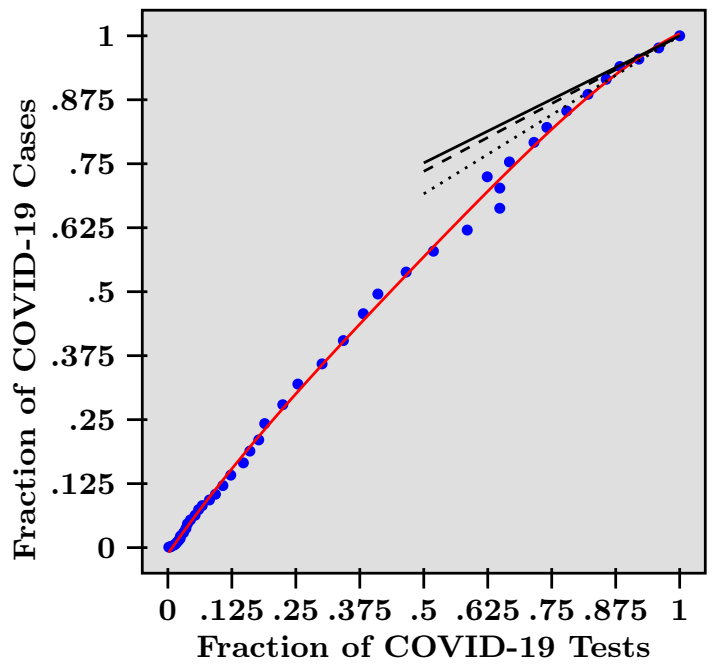

(2) Basilicata

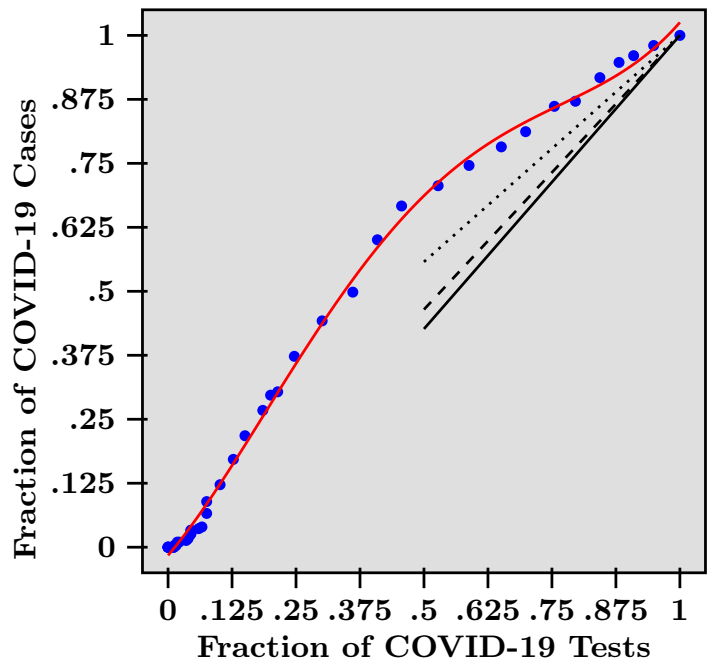

(4) Campania

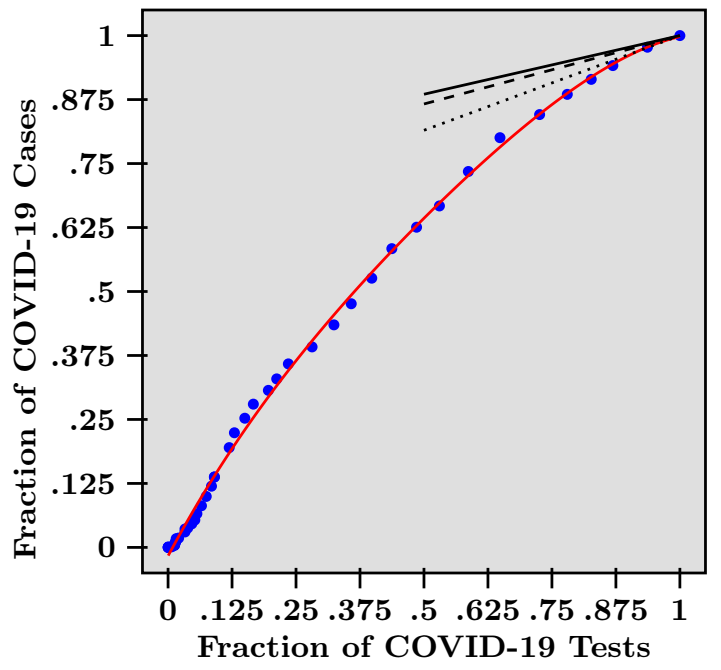

(6) Friuli Venezia Giulia

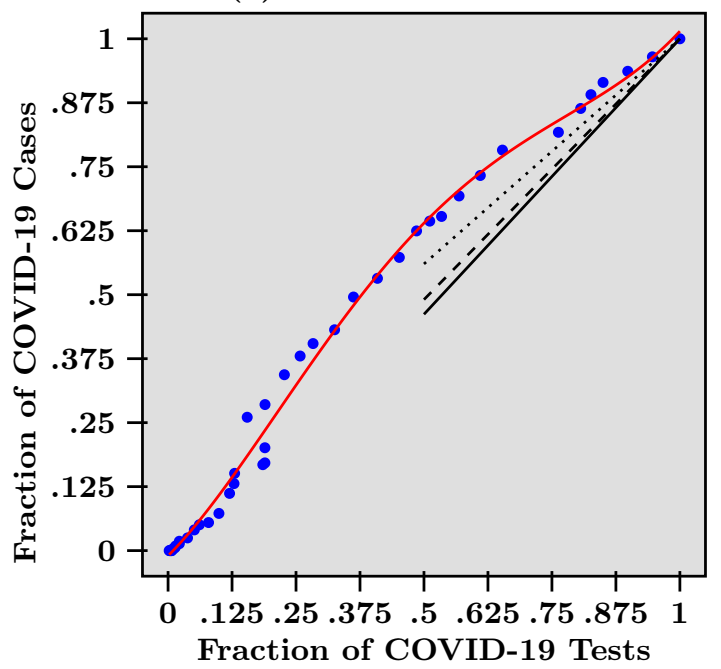


(7) Lazio

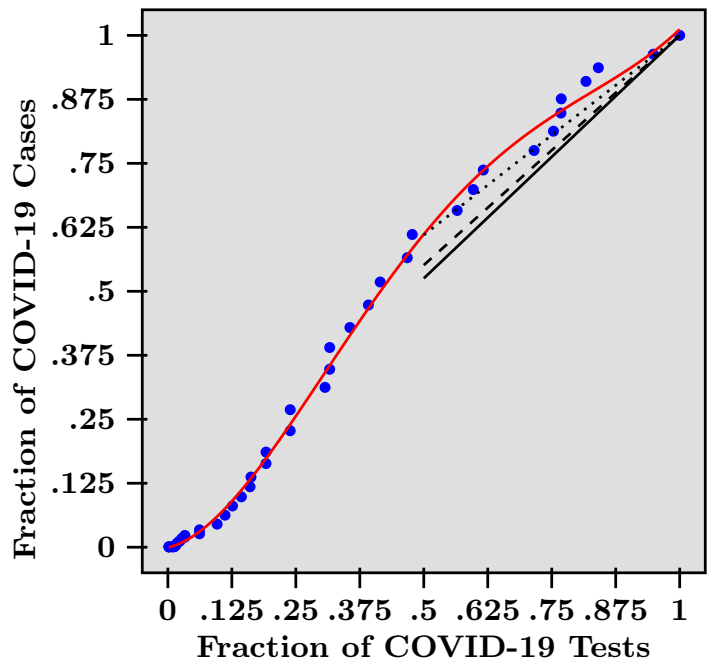

(9) Lombardia

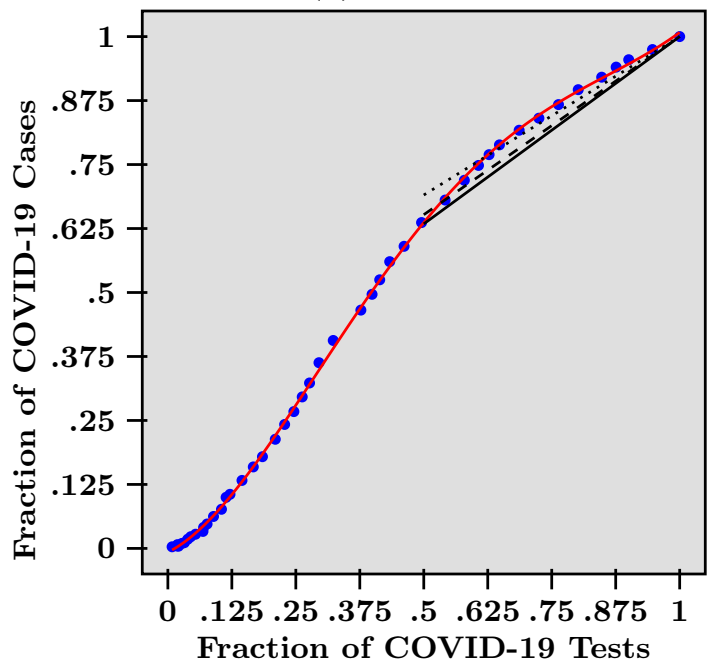

(11) Molise

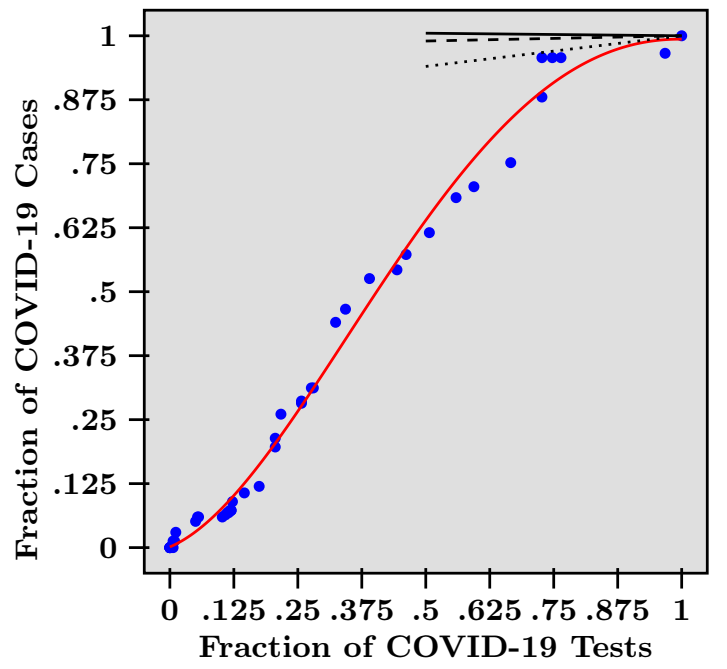

(8) Liguria

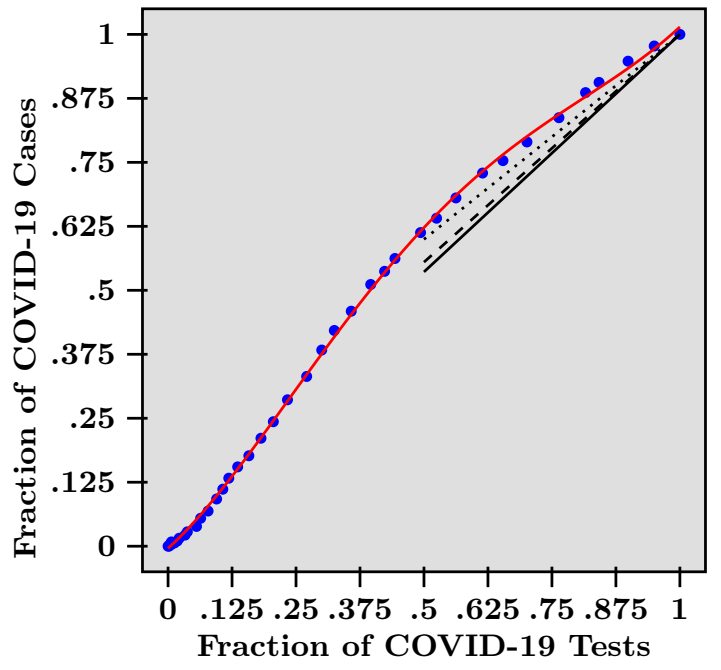

(10) Marche

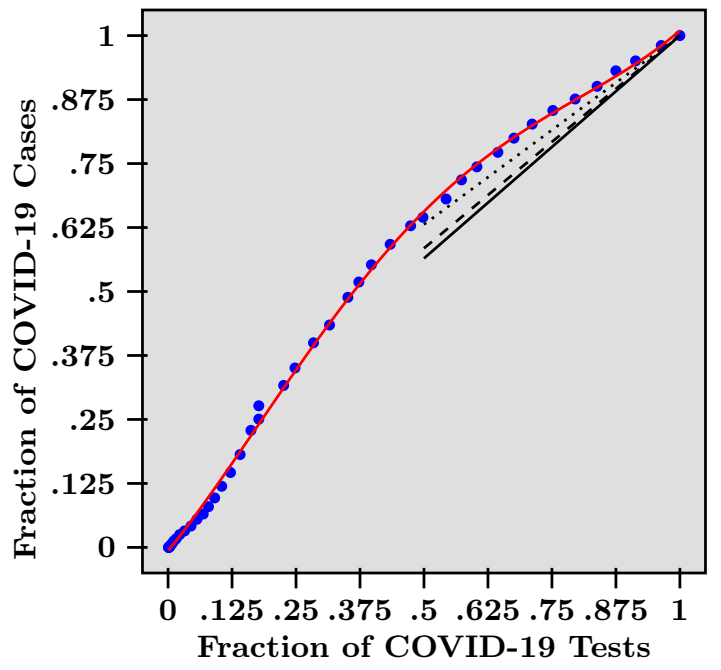

(12) P.A. Bolzano

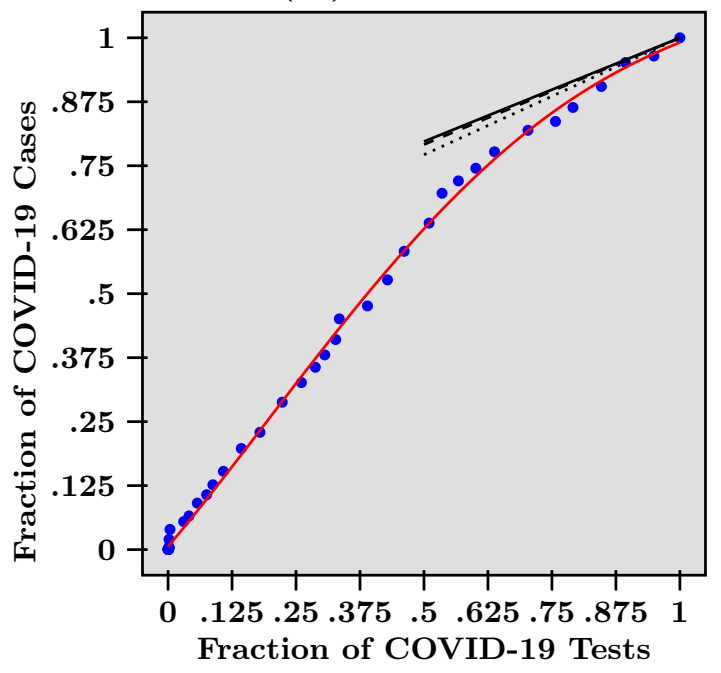


(13) P.A. Trento

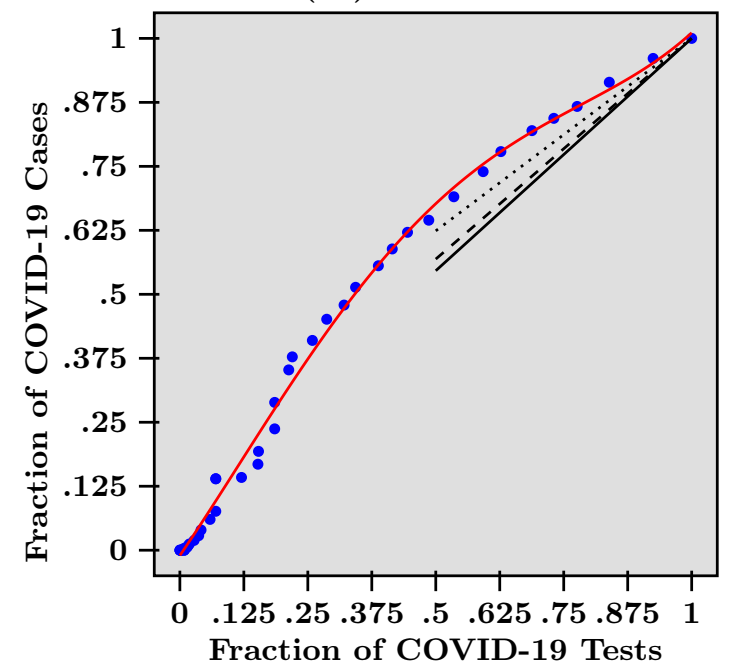

(15) Puglia

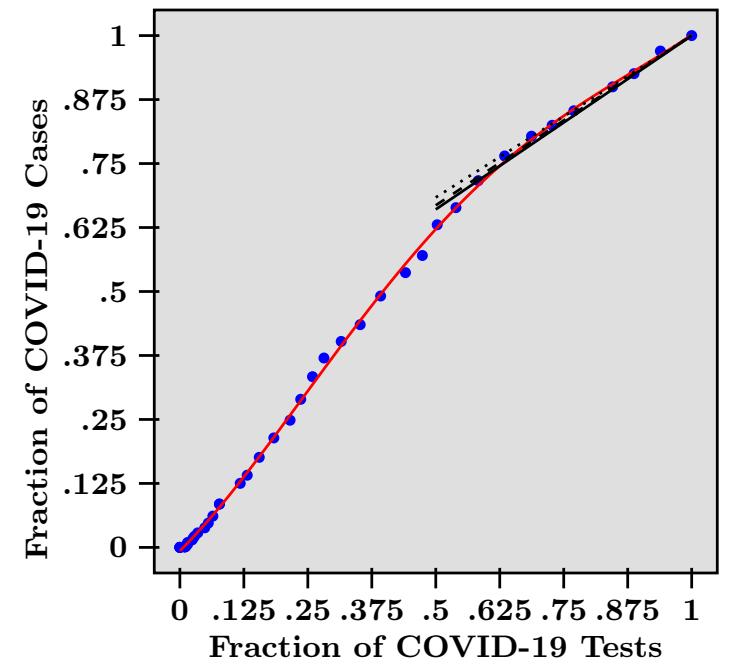

(17) Sicilia

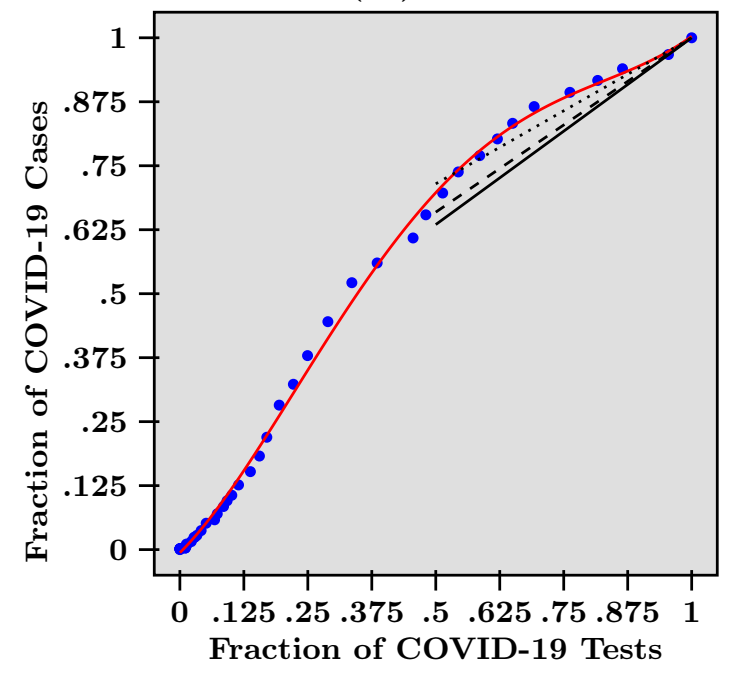

(14) Piemonte

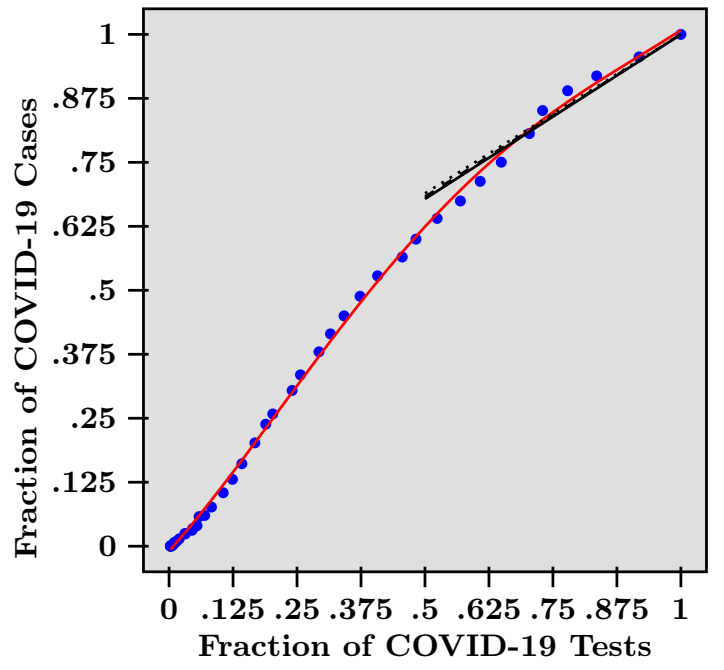

(16) Sardegna

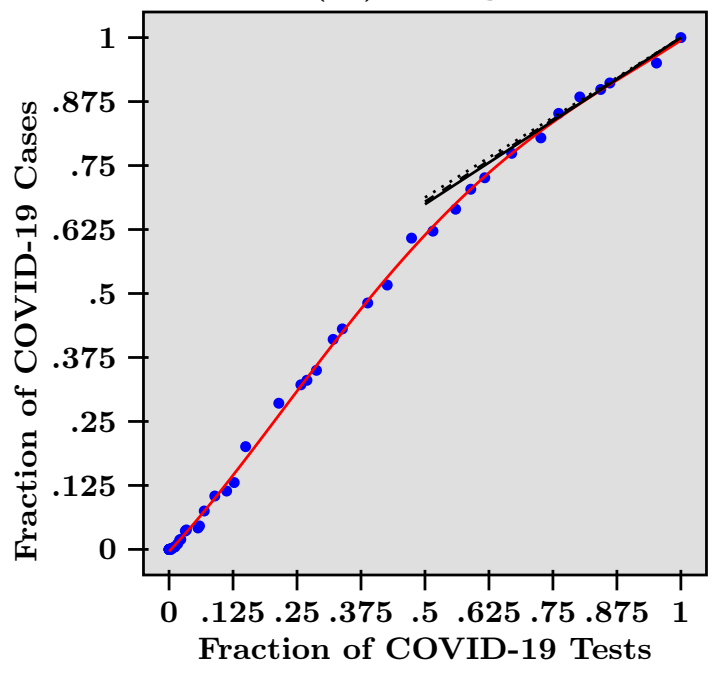

(18) Toscana

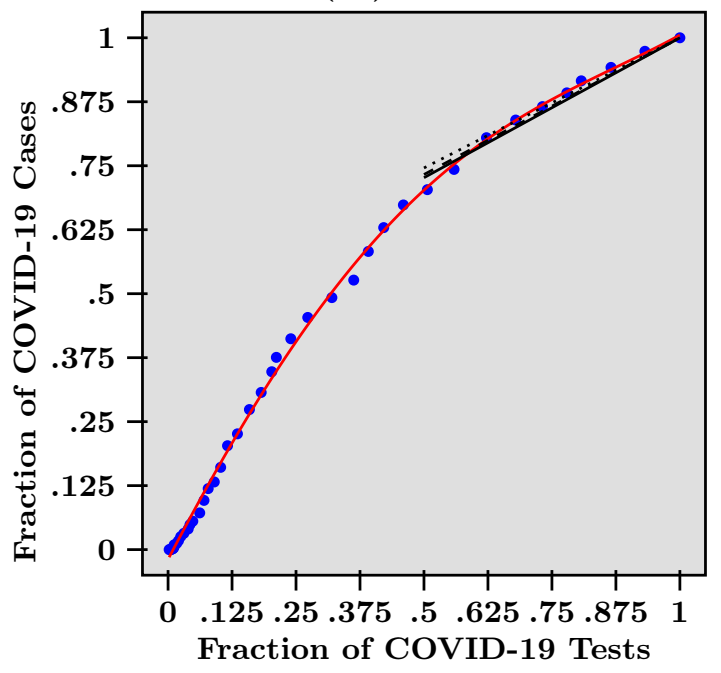


(19) Umbria

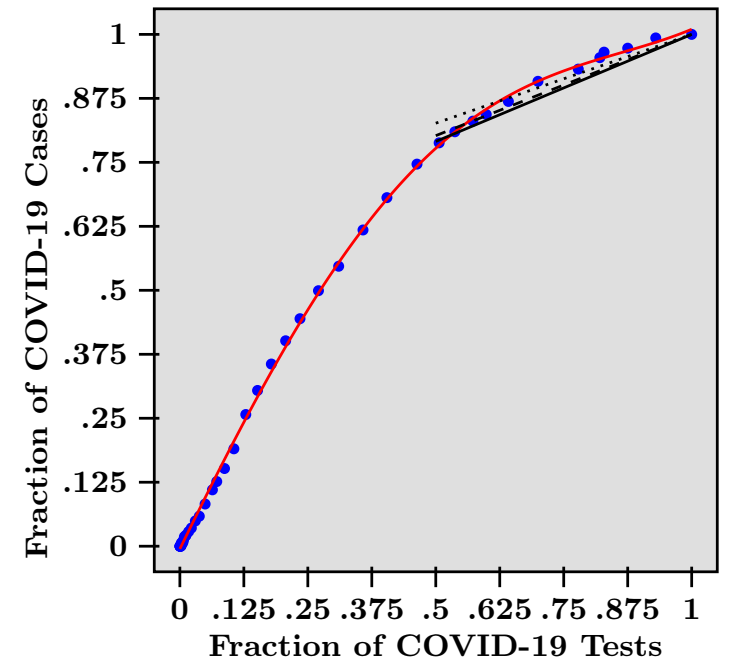

(21) Veneto

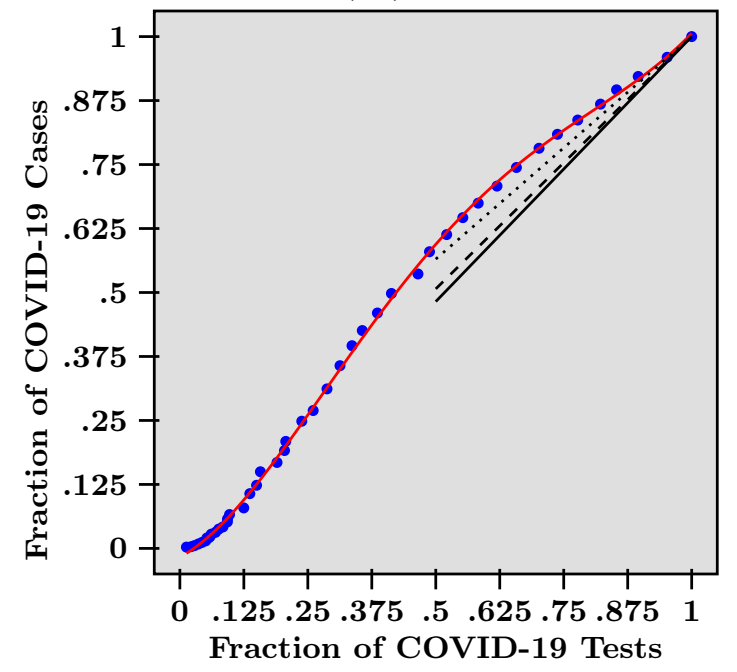

(20) Valle d'Aosta

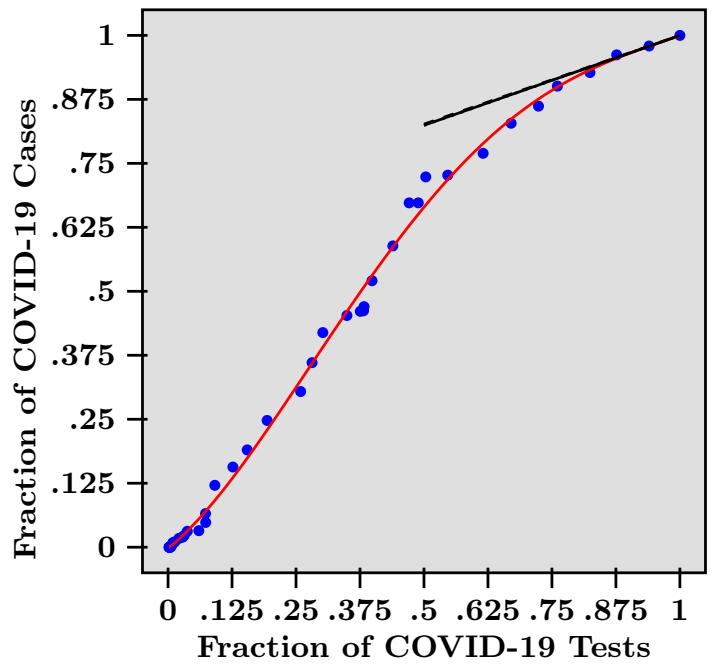




\section{B Numerical Estimates}

In the following tables, we present the estimated efficient allocations using different non-parametric estimates of the first derivative at the end date: (1) the end point estimate, (2) the mean estimate of the last $2.5 \%$ output design points and (3) the mean estimate of the last $10 \%$ outut design points. The sensitivity analysis indicates that efficient allocation shares are robust to the choice of the first estimate derivative. We consider that the mean estimate of the last $2.5 \%$ output design points offers the most versatility for our purpose in our setting.

\section{B.1 Efficient Allocations with End Point Estimate}

\begin{tabular}{|c|c|c|c|c|c|}
\hline Region & Inhabitants $\left(n_{i}\right)$ & Weight $\left(w_{i}\right)$ & Allocation $\left(a_{i}\right)$ & Allocation $\left(A_{i}\right)$ & Actual All. $\left(x_{i}\right)$ \\
\hline Abruzzo & 1.311 .580 & 1.354 & 9.27 & 4.19 & 1.970 \\
\hline Basilicata & 562.869 & 1.147 & 7.85 & 1.52 & 0.411 \\
\hline Calabria & 1.947 .131 & 0.466 & 3.19 & 2.14 & 1.853 \\
\hline Campania & 5.801 .692 & 0.229 & 1.57 & 3.14 & 3.444 \\
\hline Emilia-Romagna & 4.459 .477 & 0.497 & 3.40 & 5.23 & 9.746 \\
\hline Friuli-Venezia Giulia & 1.215 .220 & 1.077 & 7.37 & 3.09 & 3.086 \\
\hline Lazio & 5.879 .082 & 0.949 & 6.50 & 13.17 & 6.702 \\
\hline Liguria & 1.550 .640 & 0.928 & 6.35 & 3.40 & 2.176 \\
\hline Lombardia & 10.060 .574 & 0.732 & 5.01 & 17.38 & 20.862 \\
\hline Marche & 1.525 .271 & 0.871 & 5.96 & 3.13 & 2.168 \\
\hline Molise & 305.617 & -0.010 & 0.07 & -0.01 & 0.233 \\
\hline P.A. Bolzano & 520.891 & 0.405 & 2.78 & 0.50 & 2.339 \\
\hline P.A. Trento & 538.223 & 0.908 & 6.21 & 1.15 & 1.638 \\
\hline Piedmont & 4.356 .406 & 0.643 & 4.40 & 6.61 & 6.012 \\
\hline Apulia & 4.029 .053 & 0.679 & 4.65 & 6.46 & 3.052 \\
\hline Sardinia & 1.639 .591 & 0.651 & 4.46 & 2.52 & 1.038 \\
\hline Sicilia & 4.999 .891 & 0.730 & 5.00 & 8.61 & 3.353 \\
\hline Toscana & 3.729 .641 & 0.547 & 3.74 & 4.81 & 7.575 \\
\hline Umbria & 882.015 & 0.418 & 2.86 & 0.87 & 1.761 \\
\hline Valle d'Aosta & 125.666 & 0.351 & 2.40 & 0.10 & 0.366 \\
\hline Veneto & 4.905 .854 & 1.035 & 7.09 & 11.99 & 20.214 \\
\hline
\end{tabular}


B.2 Efficient Allocations with Last 2.5\% Output Design Points

\begin{tabular}{lrrrrr}
\hline \hline Region & Inhabitants $\left(n_{i}\right)$ & Weight $\left(w_{i}\right)$ & Allocation $\left(a_{i}\right)$ & Allocation $\left(A_{i}\right)$ & Actual All. $\left(x_{i}\right)$ \\
\hline Abruzzo & 1.311 .580 & 1.248 & 8.85 & 3.99 & 1.970 \\
Basilicata & 562.869 & 1.071 & 7.59 & 1.47 & 0.411 \\
Calabria & 1.947 .131 & 0.473 & 3.36 & 2.25 & 1.853 \\
Campania & 5.801 .692 & 0.267 & 1.89 & 3.78 & 3.444 \\
Emilia-Romagna & 4.459 .477 & 0.530 & 3.76 & 5.76 & 9.746 \\
Friuli-Venezia Giulia & 1.215 .220 & 1.019 & 7.22 & 3.02 & 3.086 \\
Lazio & 5.879 .082 & 0.898 & 6.36 & 12.86 & 6.702 \\
Liguria & 1.550 .640 & 0.890 & 6.31 & 3.36 & 2.176 \\
Lombardia & 10.060 .574 & 0.696 & 4.93 & 17.06 & 20.862 \\
Marche & 1.525 .271 & 0.831 & 5.89 & 3.09 & 2.168 \\
Molise & 305.617 & 0.020 & 0.15 & 0.02 & 0.233 \\
P.A. Bolzano & 520.891 & 0.417 & 2.96 & 0.53 & 2.339 \\
P.A. Trento & 538.223 & 0.862 & 6.11 & 1.13 & 1.638 \\
Piedmont & 4.356 .406 & 0.634 & 4.50 & 6.73 & 6.012 \\
Apulia & 4.029 .053 & 0.663 & 4.70 & 6.51 & 3.052 \\
Sardinia & 1.639 .591 & 0.641 & 4.55 & 2.56 & 1.038 \\
Sicilia & 4.999 .891 & 0.681 & 4.83 & 8.30 & 3.353 \\
Toscana & 3.729 .641 & 0.534 & 3.79 & 4.85 & 7.575 \\
Umbria & 882.015 & 0.396 & 2.80 & 0.85 & 1.761 \\
Valle d'Aosta & 125.666 & 0.347 & 2.46 & 0.11 & 0.366 \\
Veneto & 4.905 .854 & 0.986 & 6.99 & 11.78 & 20.214 \\
\hline \hline
\end{tabular}


B.3 Efficient Allocations with Last 10\% Output Design Points

\begin{tabular}{|c|c|c|c|c|c|}
\hline Region & Inhabitants $\left(n_{i}\right)$ & Weight $\left(w_{i}\right)$ & Allocation $\left(a_{i}\right)$ & Allocation $\left(A_{i}\right)$ & Actual All. $\left(x_{i}\right)$ \\
\hline Abruzzo & 1.311 .580 & 0.988 & 7.58 & 3.39 & 1.970 \\
\hline Basilicata & 562.869 & 0.885 & 6.79 & 1.30 & 0.411 \\
\hline Calabria & 1.947 .131 & 0.500 & 3.84 & 2.55 & 1.853 \\
\hline Campania & 5.801 .692 & 0.370 & 2.84 & 5.61 & 3.444 \\
\hline Emilia-Romagna & 4.459 .477 & 0.618 & 4.74 & 7.20 & 9.746 \\
\hline Friuli-Venezia Giulia & 1.215 .220 & 0.880 & 6.75 & 2.80 & 3.086 \\
\hline Lazio & 5.879 .082 & 0.780 & 5.99 & 11.99 & 6.702 \\
\hline Liguria & 1.550 .640 & 0.801 & 6.14 & 3.25 & 2.176 \\
\hline Lombardia & 10.060 .574 & 0.619 & 4.75 & 16.29 & 20.862 \\
\hline Marche & 1.525 .271 & 0.738 & 5.66 & 2.94 & 2.168 \\
\hline Molise & 305.617 & 0.120 & 0.92 & 0.10 & 0.233 \\
\hline P.A. Bolzano & 520.891 & 0.457 & 3.51 & 0.62 & 2.339 \\
\hline P.A. Trento & 538.223 & 0.752 & 5.77 & 1.06 & 1.638 \\
\hline Piedmont & 4.356 .406 & 0.621 & 4.77 & 7.08 & 6.012 \\
\hline Apulia & 4.029 .053 & 0.632 & 4.85 & 6.66 & 3.052 \\
\hline Sardinia & 1.639 .591 & 0.625 & 4.79 & 2.68 & 1.038 \\
\hline Sicilia & 4.999 .891 & 0.571 & 4.38 & 7.46 & 3.353 \\
\hline Toscana & 3.729 .641 & 0.509 & 3.90 & 4.96 & 7.575 \\
\hline Umbria & 882.015 & 0.347 & 2.66 & 0.80 & 1.761 \\
\hline Valle d'Aosta & 125.666 & 0.352 & 2.70 & 0.12 & 0.366 \\
\hline Veneto & 4.905 .854 & 0.869 & 6.67 & 11.15 & 20.214 \\
\hline
\end{tabular}

